\title{
NOTES
}

\section{Surface Enrichment and Bulk Morphology in Mixtures of Poly(methyl methacrylate) with Poly(dimethylsiloxane)}

\author{
Kazunori SeKI, Yongjun LeE, ${ }^{*}$ Isamu AKIBA, ${ }^{* *}{ }^{\dagger}$ and Saburo AKIYAMA \\ Department of Organic and Polymer Materials Chemistry, Faculty of Technology, \\ Tokyo University of Agriculture and Technology, Koganei, Tokyo 184-8588, Japan \\ * Research and Information Center, Dow Corning Asia, Yamakita, Kanagawa 258-0112, Japan \\ ${ }^{* *}$ Faculty of Environmental Engineering, The University of Kitakyushu, \\ 1-1 Hibikino, Wakamatsu, Kitakyushu, Fukuoka 808-0135, Japan
}

(Received January 30, 2004; Accepted April 20, 2004; Published July 15, 2004)

\begin{abstract}
KEY WORDS Poly(dimethylsiloxane) / Poly(methyl methacrylate) / Surface Enrichment / Morphology / Cross-linking / Solvent Evaporation /

[DOI 10.1295/polymj.36.556]
\end{abstract}

Because Si-containing polymers have extremely low surface energy, they show unique behavior in polymer materials. Therefore, the properties and synthesis of the Si-containing polymeric materials have been extensively investigated. ${ }^{1-15}$

The extremely low surface energy of the Si-containing polymers, such as poly(dimethylsiloxane) (PDMS), causes surface segregation in the polymer blends and block copolymer in analogy with fluorocontaining polymers. ${ }^{4-19}$ In addition, gradient morphologies are rarely formed in the immiscible polymer blends containing the PDMS or fluoro-containing polymers. ${ }^{20,21}$ This kind of heterogeneity should be originated from coupling the large difference of the surface energies of the components with the other factors dominating thermodynamic situation, molecular dynamics, and so on. ${ }^{22,23}$ Therefore, various morphologies should be prepared by adjustment balance of the surface energy and the other variable factors in these polymer blends. When these types of the polymer blends are prepared by solution casting, it has been found that rate of solvent evaporation and miscibility is one of the most dominate factors to determine the distribution of the dispersed domains. ${ }^{24-27}$ If the systems contain cross-linkable (reactive) components, the reactions should also be a dominate factor on the morphological heterogeneity. Therefore, in the polymer blends containing the cross-linkable $\alpha, \omega$-divinyl terminated PDMS, ${ }^{28,29}$ the morphologies should be changed with the heterogeneity of compositional distributions and cross-linking reaction. Thus, in this study, we investigate morphologies of the cross-linkable PDMS-containing polymer blends prepared by solution casting.
Table I. Molecular characteristics of PMMA and PDMS

\begin{tabular}{lcc}
\hline & $M_{\mathrm{n}} \times 10^{-3 *}$ & $M_{\mathrm{w}} \times 10^{-3 *}$ \\
\hline PMMA & 8.7 & 17 \\
PDMS & 1.7 & 2.2 \\
\hline
\end{tabular}

* Molecular weights were determined by gel permeation chromatography calibrated by standard polystyrene.

\section{EXPERIMENTAL}

$\alpha, \omega$-Divinyl-terminated PDMS, platinum-divinyltetramethylsiloxane $(\mathrm{Pt})$, and cyclic hydride-containing cross-linking agent $(\mathrm{CHC})$ were supplied from Dow Corning Asia Ltd. Poly(methyl methacrylate) (PMMA) was supplied from Mitsubishi Rayon Co., Ltd. Molecular characteristics of PDMS and PMMA were listed in Table I. All the samples were used as received.

PMMA/PDMS blend films containing $10 \mathrm{wt} \%$ PDMS were prepared by solution casting. The polymers were dissolved in chloroform $\left(\mathrm{CHCl}_{3}\right)$ or tetrahydrofuran (THF) at $5 \mathrm{wt} \%$. CHC ( $2 \mathrm{wt} \%$ to the PDMS) and small amount of Pt were added to them. The solutions were stirred until they became homogeneous. After that, the solvents were evaporated on glass plate for $24 \mathrm{~h}$ at ambient temperature. The resulting uncross-linked PMMA/PDMS films with $c a$. $200 \mu \mathrm{m}$ thickness were further dried in reduced pressure for 1 week. The uncross-linked PMMA/PDMS (90/10) blends prepared from $\mathrm{CHCl}_{3}$ and THF solutions are represented as UCL-C and UCL-T, respectively. Rates of solvent evaporation in preparation of the UCL-C and UCL-T are 1.3 and $25 \%$ evaporation $\min ^{-1}$, respectively. Finally, the uncross-linked films

${ }^{\dagger}$ To whom correspondence should be addressed (E-mail: akiba@env.kitakyu-u.ac.jp). 


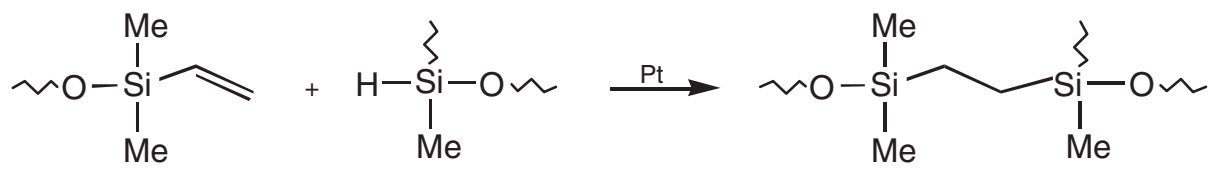

Scheme 1. Hydrosilation of vinyl-terminated PDMS.

were heated to $90^{\circ} \mathrm{C}$ and annealed for $24 \mathrm{~h}$ for crosslinking reaction as Scheme 1. The cross-linked PMMA/PDMS (90/10) films prepared from $\mathrm{CHCl}_{3}$ and THF solutions are denoted as CL-C and CL-T, respectively.

For the resulting blend films, total attenuated reflection Fourier transform infrared spectroscopy (ATRFTIR), scanning electron microscopy (SEM), and energy dispersive spectroscopy (EDS) were carried out. ATR-FTIR measurements were performed using a JEOL JIR-Winspec 35 FT-IR with a Zn-Se prism at a resolution of $2 \mathrm{~cm}^{-1}$. SEM observations for the bulk morphologies of the films were performed using a Hitachi S-800 field emission scanning microscope at an accelerating voltage of $15 \mathrm{kV}$. For SEM observations, films were frozen in liquid $\mathrm{N}_{2}$ and divided vertically. The resulting samples were coated by Au. EDS measurements for surfaces of air and substrate sides of the uncross-linked films were performed using a Philips EDAXPV99001 attached to the SEM apparatus. All the surfaces of films were simultaneously coated by Au in vacuo for 1 min to be constant thickness of Au layer for all the samples.

\section{RESULTS AND DISCUSSION}

Figure 1 shows ATR-FTIR spectra for the air-side surfaces of UCL-C, UCL-T, PMMA, and PDMS. The absorbance peaks at 1730,990 , and $790 \mathrm{~cm}^{-1}$ are attributed to carbonyl stretching band $\left(v_{\mathrm{C}=\mathrm{O}}\right)$ of PMMA, Si-O-Si $\left(v_{\mathrm{Si}-\mathrm{O}-\mathrm{Si}}\right)$ of PDMS, and $\mathrm{Si}-\mathrm{C}$ stretching band $\left(v_{\mathrm{Si}-\mathrm{C}}\right)$ of PDMS, respectively. Because the air-side surface of the UCL-C film indicates the $v_{\mathrm{C}=\mathrm{O}}, v_{\mathrm{Si}-\mathrm{O}-\mathrm{Si}}$, and $v_{\mathrm{Si}-\mathrm{C}}$, both PMMA and PDMS coexist at the air-side surface of the UCL-C film. On the other hand, the spectrum of the air-side surface of the UCL-T closely corresponds to that of only the PDMS. This means that the air-side surface of the UCL-T film is covered with only PDMS. Corresponding results are also obtained by EDS measurements. Figures 2 and 3 show EDS spectra for the air- and substrate-side surfaces of the UCL-C and UCL-T films, respectively. In both figures, the peaks at 1.75 and $2.15 \mathrm{keV}$ are originated from $\mathrm{Si}$ and $\mathrm{Au}$ coating the surfaces of the films, respectively. ${ }^{30}$ Because thickness of the Au layer is constant for each surface, we can qualitatively compare composition of the PDMS existing at surfaces of the UCL-C and UCL$\mathrm{T}$ films using the integrations of the Au peak as a ref-

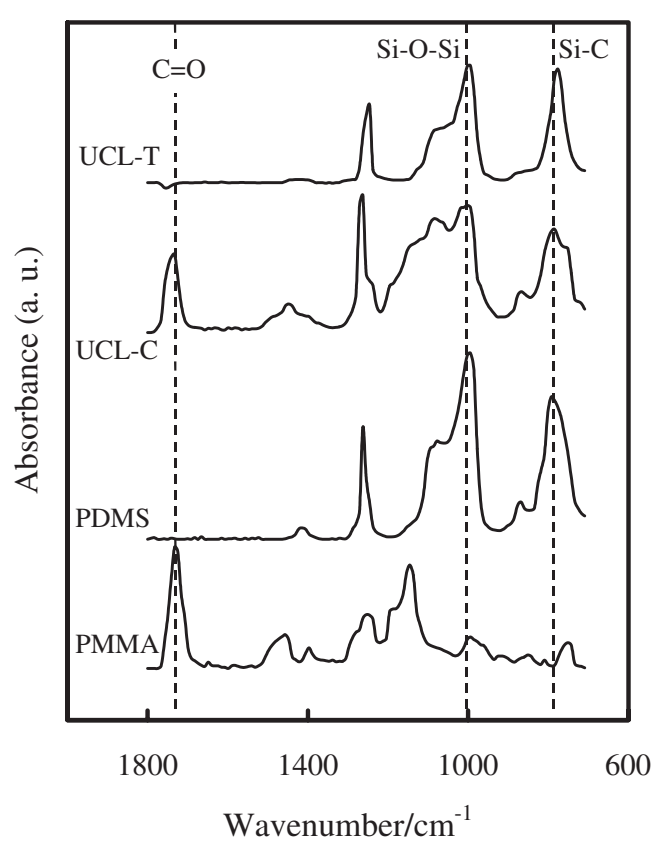

Figure 1. ATR-FTIR spectra for air-side surfaces of UCL-C, UCL-T, PDMS, PMMA films.

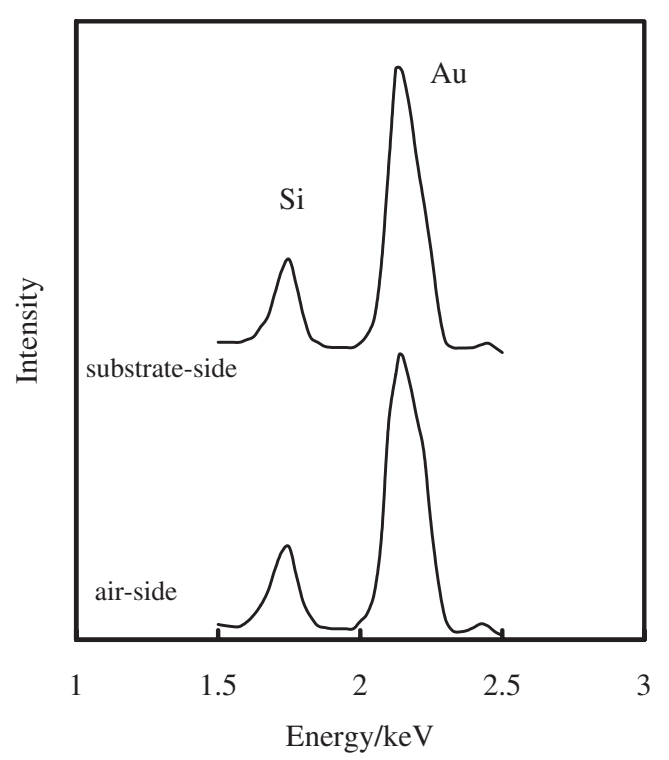

Figure 2. EDS spectra for air- and substrate-side surfaces of the UCL-C films.

erence. In Figure 2, intensities of Si peaks from both surfaces are almost same. Therefore, the composition of the PDMS is not owing to surfaces in the UCL-C. On the other hand, the Si peak from air-side surface is much stronger than that from substrate-side surface in the UCL-T. Among the Si peaks from both surfaces of 


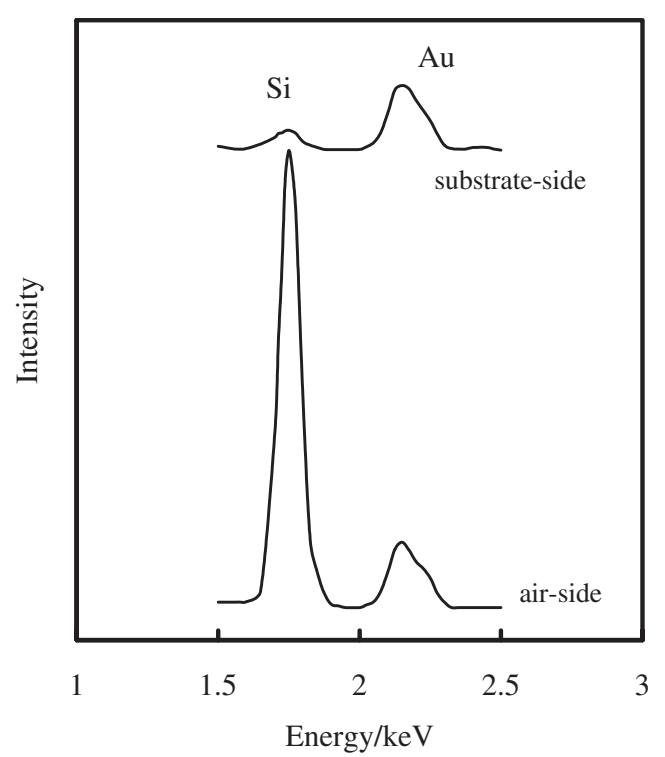

Figure 3. EDS spectra for air- and substrate-side surfaces of the UCL-T films.

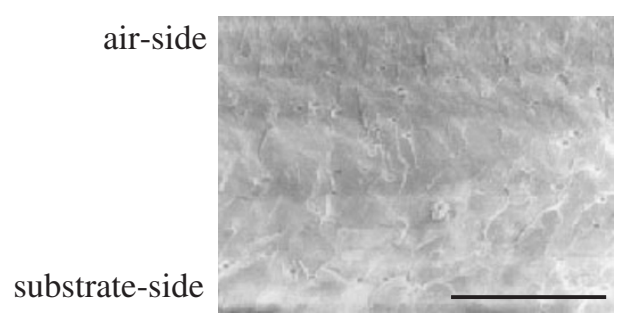

(a)

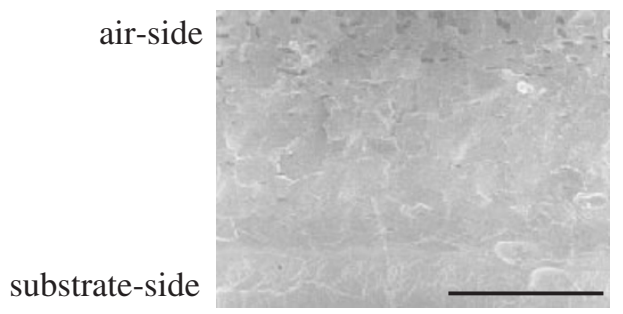

(b)

Figure 4. SEM micrographs for cross-sections of the uncrosslinked PMMA/PDMS (90/10) blend films: (a) UCL-C, (b) UCLT. Scale bars correspond to $100 \mu \mathrm{m}$.

the UCL-C and UCL-T, the intensity from the air-side surface of the UCL-T is extremely intensive. Therefore, the air-side surface of the UCL-T film is covered by PDMS component.

Figures $4 \mathrm{a}$ and $\mathrm{b}$ show SEM micrographs for crosssections of the UCL-C and UCL-T films, respectively. In these photos, the gaping holes in the observed faces are originated from the PDMS droplets. As can be seen Figure 4a, the distribution of the PDMS phases is impartial throughout the cross-section of the UCL-C film. On the contrary, the distribution of the PDMS droplets in the UCL-T film inclines toward air-side surface, although they also exist inside of the film. The cross-section of the UCL-T film shows gradient morphology in which the sizes of the PDMS droplets are enlarged with approaching air-side surface. In addition, the PDMS layer with fluidity is formed at the surface of the UCL-T film, although the appearance can not be shown here because of collapse of the PDMS layer through the SEM operation. The features of the SEM micrographs are closely corresponding to the results of ATR-FTIR and EDS analyses. Because of extremely low surface energy of PDMS, it generally tends to segregate to air-side surfaces of films of the PDMS-containing polymer blends and block copolymers. When the surface segregation couples with phase separation, the gradient morphology should be formed in the polymer blend. ${ }^{26,27}$ In fluoro/acrylate polymer blends of which phase behavior is closely similar to that of the PMMA/PDMS blends in this study, when the rate of solvent evaporation $(R)$ is lower than $2.5 \%$ evaporation $\min ^{-1}$, air-side surface is covered by the component with lower surface energy. ${ }^{27}$ The $R$ in the preparation of UCL-T film was $1.3 \%$ evaporation $\min ^{-1}$. Therefore, it is considered that the evaporation rate of THF casually adjusts balances of the phase separation, segregation of PDMS to air-side surface, and solidification to form the gradient morphology in the PMMA/PDMS blend. On the other hand, the evaporation rate of $\mathrm{CHCl}_{3}$ ( $c a .25 \%$ evaporation $\mathrm{min}^{-1}$ ) is extremely faster than that of THF $\left(1.3 \%_{\text {evaporation }} \mathrm{min}^{-1}\right)$. Apparent fluidity of the blend solutions disappears when $c a$. $70 \%$ of solvent was evaporated. Therefore, the UCL-C is solidified within $3 \mathrm{~min}$, although the UCL-T takes about $1 \mathrm{~h}$. The extremely rapid evaporation of $\mathrm{CHCl}_{3}$ should prevent the UCL-C from developing the phase separation. Therefore, the homogeneously dispersed morphology should be observed in the cross-section of the UCL$\mathrm{C}$ film. It is expected that the difference of the morphology between the UCL-T and UCL-C films is reflected to the morphologies of the cross-linked films.

Figure 5 shows SEM micrographs of cross-sections of the CL-C and CL-T films. The morphology of the CL-C is seemed to be same as that of the UCL-C. Since the PDMS domains are individually dispersed in glassy PMMA matrix in the UCL-C, the PDMS droplets can not coalesce each other. Therefore, the morphology of the CL-C is identical with that of the UCL-C. On the other hand, the irregular morphology in which the PMMA domains are encapsulated in PDMS matrix is observed for the CL-T. The size of the dispersed PMMA droplet in the CL-T is increasing with closing the substrate-side surface. On the other hand, because population of the PDMS becomes higher with closing the air-side surface in the CL-T, interconnection of the PDMS droplets should be formed in the vicinity of the air-side surface with developing 
Morphology of PMMA/PDMS Blends

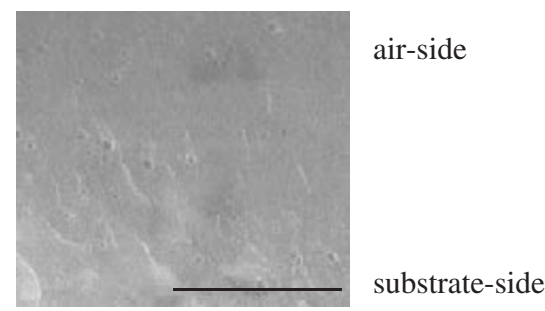

(a)

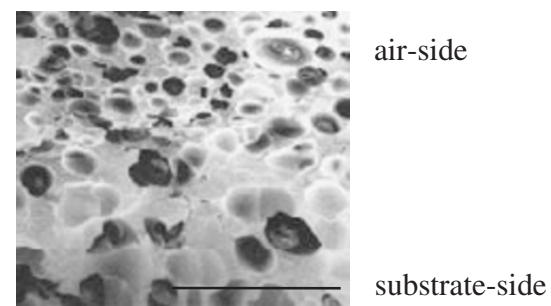

(b)

Figure 5. SEM micrographs for cross-sections of the crosslinked PMMA/PDMS (90/10) blend films: (a) CL-C, (b) CL-T. Scale bars correspond to $100 \mu \mathrm{m}$.

phase morphology. The continuity of the PDMS phases should be developed due to relatively slow rate of the cross-linking reaction, although sufficient understandings are not obtained. Therefore, the heterogeneous morphology in which the irregularly dispersed PMMA (major component) domains are encapsulated with the PDMS (minor component) matrix would be formed in the CL-T film. Thus the morphologies of the cross-linked PMMA/PDMS blends are dominated by uncross-linked situations. It has been well-known that phase separated structures of immiscible polymer blends are possible to be controlled by rate of solvent evaporation, ${ }^{31}$ reaction, ${ }^{30}$ and so on. Therefore, the results in this study indicate that the various morphologies in the immiscible polymer blends should be controlled by coupling the heterogeneity of the distribution of the components, such as surface segregation, with evolutions of the morphology in the phase separation process.

Acknowledgment. We are grateful to Dr. Saruyama of Dow Corning Asia Ltd. for a generous gift of the PDMS samples used in this study.

\section{REFERENCES}

1. R. L. Schmitt, J. A. Gardella, Jr., and H. Magill, L. Salvati, Jr., and R. L. Chin, Macromolecules, 18, 2675 (1985).

2. R. L. Schmitt, J. A. Gardella, and L. Salvati, Jr., Macromolecules, 19, 648 (1986).

3. N. M. Patel, D. W. Dwight, J. L. Hedrick, D. C. Webster, and J. E. McGrath, Macromolecules, 21, 2689 (1988).

4. J. M. DeSimone, G. A. York, J. E. McGrath, A. S. Gozdz, and M. J. Bowden, Macromolecules, 24, 5330 (1991).

5. E. K. Mann and D. Langevin, Langmuir, 7, 1112 (1991).

6. X. Chen, J. A. Gardella, Jr., and P. L. Kumler, Macromolecules, 25, 6621 (1992).

7. F. E. Runge and H. Yu, Langmuir, 9, 3191 (1993).

8. X. Chen and J. A. Gardella, Jr., Macromolecules, 27, 3363 (1994).

9. S. Petitjean, G. Ghitti, R. Jerome, Ph. Teyssie, J. Marien, J. Riga, and J. Verbist, Macromolecules, 27, 4127 (1994).

10. H. Y. Erbil, B. Yasar, S. Suzer, and B. M. Baysal, Langmuir, 13, 5484 (1997).

11. J. Chen and J. A. Gardella, Jr., Macromolecules, 31, 9328 (1998).

12. M. A. Childs, D. D. Matlock, J. R. Dorgan, and T. R. Ohno, Biomacromolecules, 2, 526 (2001).

13. C. M. Mahoney, J. A. Gardella, Jr., and J. C. Rosenfeld, Macromolecules, 35, 5256 (2002).

14. P. Viville, R. Lazzaroni, P. Dubois, A. Kotzev, Y. Geerts, G. Borcia, and J.-J. Pireaux, Biomacromolecules, 4, 696 (2003).

15. S. Kawahara, A. Nagai, T. Kazama, A. Takano, and Y. Isono, Macromolecules, 37, 315 (2004).

16. S. K. Thanawala and M. K. Chaudhury, Langmuir, 16, 1256 (2000).

17. Y. Kano, K. Ishikura, S. Kawahara, and S. Akiyama, Polym. J., 24, 135 (1992).

18. J. F. Hester and A. M. Mayes, J. Membrane Sci., 202, 119 (2002).

19. D. H. Gracias, Z. Chen, Y. R. Shen, and G. A. Somorjai, Acc. Chem. Res., 32, 930 (1999).

20. Y. Kano, S. Akiyama, H. Sano, and H. Yui, J. Electron Microsc., 44, 344 (1995).

21. Y. J. Lee, I. Akiba, and S. Akiyama, J. Appl. Polym. Sci., 86, 1736 (2002).

22. X.-M. Xie, M. Matsuoka, and K. Takemura, Polymer, 33, 1996 (1992).

23. X.-M. Xie, Y. Chen, Z.-M. Zhang, A. Tanioka, M. Matsuoka, and K. Takemura, Macromolecules, 32, 4424 (1992).

24. H. Zhuang and J. A. Gardella, Jr., Macromolecules, 30, 3632 (1997).

25. J. Chen and J. A. Gardella, Jr., Macromolecules, 31, 9328 (1998).

26. Y. Kano, M. Inoue, I. Akiba, S. Akiyama, H. Sano, and H. Yui, J. Adhes. Sci. Technol., 12, 415 (1998).

27. S. Akiyama, N. Tsukiji, I. Akiba, M. Inoue, and Y. Kano, Polym. Int., 50, 659 (2001).

28. K. T. Lim, S. E. Webber, and K. P. Johnston, Macromolecules, 32, 2811 (1999).

29. S. K. Thanawala and M. K. Chaudhury, Langmuir, 16, 1256 (2000).

30. B. Lestriez, J.-P. Chapel, and J.-F. Gérard, Macromolecules, 34, 1204 (2001).

31. T. Inoue, T. Ougizawa, O. Yasuda, and K. Miyasaka, Macromolecules, 18, 57 (1985). 